ANNOUNCEMENT

\title{
Announcement of changes to the editorial board
}

Published online: 9 November 2020

(C) Springer Nature B.V. 2020

Jean-Pierre Timmermans has served as an Associate Editor of the journal for many years and is stepping down. His outstanding contribution has been much appreciated and we thank him. Jean-Pierre will continue to serve as a member of the Editorial Board. Brian Gulbransen, who has an excellent publishing record relating to purinergic signalling in the gastrointestinal tract, has agreed to join the Associate Editorial board.

Publisher's note Springer Nature remains neutral with regard to jurisdictional claims in published maps and institutional affiliations. 